\section{Disfunción valvular protésica con síntomas atípicos. ¿Endocarditis o trombosis?}

\section{Sr. Director:}

El mal funcionamiento de una prótesis valvular cardiaca puede ser debido a trombosis, infección, deterioro estructural o regurgitación paravalvular, pudiendo coexistir dichas entidades, y siendo en ocasiones difíciles de diferenciar. Describimos el caso de un paciente con clínica inicial de anemia y alteraciones del sedimento urinario en el que se detectó disfunción protésica en estadios avanzados, siendo la etiología de dicha disfunción difícil de determinar hasta que se realizó el recambio valvular.

Varón de 55 años portador de prótesis mitral mecánica tipo Carbomedics por estenosis reumática. Aqueja, desde el mes siguiente a la intervención, hematuria y astenia que motivan su hospitalización al año. A la exploración destacan hepatoesplenomegalia y hematuria macroscópica, y en los análisis, Hemoglobina (Hgb) 7,3 gr/dl, ferropenia, hiperbilirrubimemia indirecta, aumentos de VSG y LDH, haptoglobina baja y test de Coombs normal. Por síndrome miccional de realiza urocultivo aislándose Staphylococcus Epidermidis (SE). Se procede a transfusión y antibioterapia oral, siendo dado de alta con el diagnóstico de anemia secundaria a hemolisis protésica y a hematuria debida a infección urinaria. A los cinco meses reingresa por edema agudo de pulmón. A la auscultación cardiaca destaca soplo sistólico rudo audible en todos los focos y en los análisis INR 2,1, $\mathrm{Hgb} \mathrm{8,6} \mathrm{gr/dl,} \mathrm{datos} \mathrm{de} \mathrm{hemolisis,} \mathrm{aumento} \mathrm{de}$ VSG, PCR, inmunocomplejos circulantes (IgCC) y complemento, y en orina leucocituria y hematuria con cultivo negativo. Se realiza Ecocardiograma Transtorácico (ETT) y Transesofágico (ETE) que muestran imágenes vegetantes adheridas a la prótesis mitral (Fig. 1) que determinan disfunción protésica con severa obstrucción y regurgitación moderada. Los hemocultivos seriados resultan repetidamente negativos. Se analizan los estudios de coagulación previos evidenciando cifras de anticoagulación infraterapéuticas de forma repetida por lo que se sospecha trombosis sobre prótesis y se inicia tratamiento con ácido acetil salicílico, heparina sódica y realiza fibrinolisis con t-PA. El ETE posterior muestra menor regurgitación sin visualizar imágenes adheridas a la prótesis. La situación clíni-

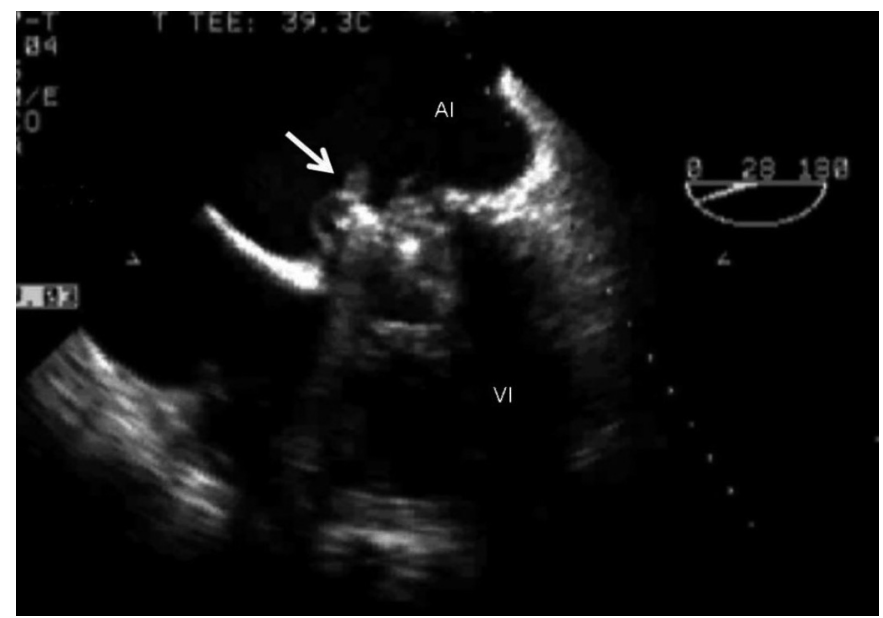

Fig. 1. ETE que muestra imágenes vegetantes (flecha) sobre prótesis mecánica mitral con limitación de la apertura de los discos. Al: aurícula izquierda; VI: ventrículo izquierdo. ca posterior es desfavorable reapareciendo signos y síntomas de insuficiencia cardiaca procediéndose a recambio de prótesis, objetivando dehiscencia protésica con aspecto de endocarditis, y se mantiene antibioterápia específica durante 6 semanas. En el cultivo del tejido paravalvular se aísla SE. Al año el paciente se encuentra asintomático y sin hematuria ni anemia.

Las alteraciones Ecocardiográficas en la morfología y movimiento valvulares plantean el diagnóstico diferencial entre vegetación, pannus o trombosis valvular obstructiva $(1,2)$ (TVO), requiriendo de la valoración clínica para su diferenciación. Esplenomegalia, anemia y fiebre son la triada clásica de endocarditis bacteriana. Sin embargo, su presencia simultánea no es habitual, siendo la esplenomegalia infrecuente y apareciendo fundamentalmente en endocarditis crónicas. La endocarditis protésica tardía abarca el periodo comprendido desde los sesenta días del implante hasta un año después del mismo (3) y en los análisis suele haber aumentos de VSG, PCR e IgCC; hipocomplementemia, anemia normocítica y leucocitos normales o ligeramente elevados. Aunque el diagnóstico de endocarditis bacteriana se basa en los criterios de Duke, se ha sugerido la necesidad de ampliar los criterios menores para aumentar la sensibilidad, incluyendo valores de VSG y PCR, así como presencia de acropaquias, esplenomegalia y hematuria (4). El pannus suele aparecer en prótesis con antigüedad superior a cinco años y cursa de forma crónica mientras que la trombosis cursa con clínica aguda o subaguda en pacientes hipocoagulados (5). Ante la sospecha de TVO puede optarse por fibrinolisis o recambio valvular. Para algunos autores la primera está contraindicada en casos de trombo móvil mayor de $5 \mathrm{~mm}$, dado su elevado riesgo embolígeno $(6,7)$. Para otros, dicho riesgo viene determinado por la velocidad de perfusión del trombolítico, siendo la fibrinolisis el tratamiento de elección independientemente del grado de obstrucción y la clase funcional de la NYHA (8-10) y está contraindicada en la endocarditis por el riesgo de transformación hemorrágica de embolismos sépticos cerebrales asintomáticos. Nuestro paciente presentaba un criterio clínico menor (prótesis) y uno mayor (masa y dehiscencia) constituyendo endocarditis posible según criterios de Duke, no obstante, ante el estado de hipocoaglabilidad y ausencia de otros hallazgos clínicos, se consideró más plausible la posibilidad de trombosis valvular. Destacamos la necesidad de la sospecha clínica de endocarditis en todo paciente con disfunción protésica valvular aunque los síntomas de infección típicos no estén presentes.

\section{I. de la Puerta González Miró, G. Piñol Ripoll' ${ }^{1}$, I. Lacambra Blasco, A. del Río Ligorit}

Servicio de Cardiología. 'Servicio de Neurología. Hospital Clínico Universitario Lozano Blesa. Zaragoza

1. Lengyel M. Management of prosthetic valve trombosis. J Heart Valve Dis 2004; 13: 329-34.

2. García del Castillo H, Evangelista Masip A. Valvulopatías XI. Disfunción potésica. Rev Esp Cardiol 1990; 43: 569-80

3. Karchmer AW. Infective endocarditis. Braunwald's Heart disease, 5th ed, vol 2. Philadelphia:WB Saunders; 1997. p. 1077-104.

4. Lamas CC, Eyken SJ. Suggested modifications to the Duke criteria for the clinical diagnosis of native valve and prosthetic valve endocarditis: analysis of 118 pathologically proven cases. Clin Infect Dis 1997; 25: 713-9.

5. Azpitarte J, Sánchez Ramos J, Urda Tomás, Vivancos R, Oyonarte JM, Malpartida F. Trombosis valvular protésica: ¿Cuál es la terapia inicial más apropiada? Rev Esp Cardiol 2001; 54: 1367-76.

6. Mantenga R, Souto JC, Altes A, Mateo J, Arís A, Domínguez JM, et al. Short-course thrombolysis as the first line of therapy for cardiac valve thrombosis. J Torca Cardiovasc Surgery 1998; 115: 780-4. 
7. Roundaut R, Labbe T, Lorient Roudaunt MF. Mechanical cardiac valve thrombosis: is fibrinolysis justified? Circulation 1992; 86 (Supl. 2): 815 .

8. Özkan M, Kaymaz C, Kirma C, Sönmez K, Ózdemir N, Balkanay M, et al. Intravenous thrombolytic treatment of mechanic valve trombosis: A study using serial transesophageal echocardiography. J Am Coll Cardiol 2000; 35: 1881-9.

9. Lengyel M. Management of prosthetic valve trombosis. J Heart Valve Dis 2004; 13: 329-34.

10. ACC/AHA guidelines for the management of patients with valvular heart disease. A report of the American College of Cardiology/American Heart Association. Task Force on Practice Guidelines (Committee on Management of Patients with Valvular Heart Disease). J Am Coll Cardiol 1998; 32 (5): 1486-588

\section{Fiebre de origen desconocido y líquen plano en pene}

\section{Sr. Director:}

La enfermedad de Crohn es una patología inflamatoria crónica intestinal cuya forma de presentación más frecuente es la aparición de episodios de dolor abdominal, diarrea y pérdida ponderal. En otras ocasiones puede comenzar como un cuadro más larvado, con sintomatología inespecífica, con las complicaciones características de la enfermedad, tanto del tracto gastrointestinal como de otras partes del cuerpo, o con manifestaciones extraintestinales. Presentamos un caso de aparición atípica de la enfermedad, cuya clínica inicial consistió únicamente en episodios repetidos de fiebre de origen desconocido y en el que la evolución y la indagación exhaustiva de los antecedentes personales y familiares fueron determinantes para su diagnóstico.

Varón de 36 años diagnosticado de liquen plano 7 años antes, que afectaba a extremidades y al pene, con múltiples recidivas. Estaba siendo estudiado ambulatoriamente desde hacía 8 meses por episodios de fiebre intermitente, autolimitados, de unos 3 días de duración, de hasta $40{ }^{\circ} \mathrm{C}$, sin focalidad y que habían comenzado un año antes de acudir a la consulta. Desde el inicio de su proceso había presentado varios flemones bucales atribuidos a caries y un episodio de parálisis facial periférica idiopática, resuelto. Actualmente se encontraba con debilidad del hombro derecho e incapacidad para la abducción de esa extremidad, siendo diagnosticado de "escápula alada". En el momento actual ingresó en el servicio de medicina interna por un nuevo episodio de fiebre de $38^{\circ} \mathrm{C}$ y dolor abdominal difuso, tipo cólico, acompañado de una deposición blanda. El paciente refería en los días previos empeoramiento de las lesiones del pene, con despeños diarreicos desde hacía meses, coincidiendo con el comienzo de la fiebre y alguna rectorragia de escasa cuantía en las últimas semanas.

En la exploración abdominal destacaba la palpación del polo inferior del bazo. En el pene tenía unas úlceras lineales con base eritematosa, y muy dolorosas al tacto. También existía limitación para la abducción del miembro superior derecho.

De las pruebas realizadas en la consulta disponíamos de un EMG del miembro superior derecho con afectación del nervio supraescapular y del torácico largo, bien por desmielinización o por compresión. Una TAC abdominal con esplenomegalia homogénea. Una IgM positiva para CMV (coincidente con la aparición de la escápula alada), infección pasada para Epstein Barr, anti HBs positivo. VIH, VHC, ricketsias, mantoux, lues, aglutinaciones brucella y salmonella fueron negativos. ANAs negativos. En el ingreso actual destacaba un hemograma y bioquímica con perfil renal y hepático normal. PCR 77. Proteinograma con leve aumento de alfa1, alfa2. Beta 2 microglobulina elevada. En la orina no había alteraciones. Los hemocultivos fueron negativos. Serología a Leishmania en orina negativa. RX Tórax y Abdomen: normal. El estudio de RM del plexo braquial derecho no mostraba alteraciones en la morfología e intensidad de señal de las estructuras, sin lesión ocupante de espacio, o signos inflamatorios de las fibras nerviosas. En la eco abdominal: Esplenomegalia homogénea.

Hasta que el paciente ingresó no había mencionado, en ningún momento, la coincidencia de la fiebre con los despeños diarreicos y solo lo hizo cuando fue preguntado expresamente sobre ello. Tampoco teníamos información sobre los antecedentes familiares, que en este caso nos ayudaron, en gran medida, al diagnóstico final, al conocer la existencia de un hermano afecto de enfermedad inflamatoria intestinal (EII). Por todo ello realizamos una colonoscopia observando un área ulcerada a los $15 \mathrm{~cm}$ del ano, de la que se tomaron biopsias cuyos resultados dieron datos de inflamación aguda y crónica, siendo el resto del colon normal con biopsias sin alteraciones. Se consiguió penetrar en ileon distal y a pesar de la mala visualización se tomó una biopsia de una ulceración aftoide, obteniendo en la muestra tejido de granulación e inflamación aguda. Decidimos completar el estudio con un transito gastrointestinal (Fig. 1) donde se objetivó un estrechamiento del tramo final del intestino delgado (signo de la cuerda) con úlceras múltiples y pseudopólipos compatible con enfermedad de Crohn. El Servicio de Dermatología confirmó que las lesiones del pene eran un brote de liquen plano con esclerosis, por el que el servicio de Urología realizó cirugía por parafimosis. Se inició tratamiento con corticoides y mesasalazina. En las revisiones posteriores el paciente se encuentra estable y fue tratado por el servicio de rehabilitación de la afección del miembro superior derecho, con normalización de la movilidad.

La enfermedad de Crohn, aunque no sea lo habitual, puede manifestarse como una fiebre de origen desconocido y sin una clínica gastroenterológica clara, al menos en su comienzo $(1,2)$. Es por ello que ha de estar presente en nuestro diagnóstico diferencial cuando un paciente es estudiado por esta causa (3). Es frecuente la relación de la EII con procesos cutáneos, siendo los más conocidos el pioderma gangrenoso y el eritema nodoso. Se revisó la bibliografía buscando relación entre la enfermedad de Crohn y el

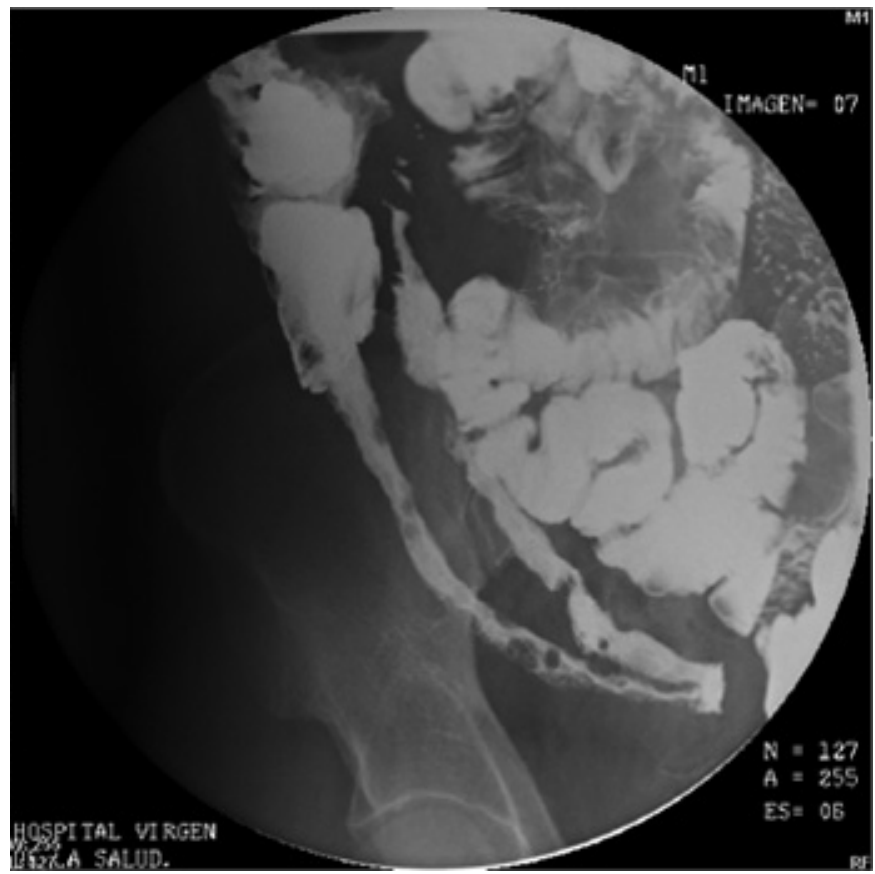

Fig. 1. Tránsito gastrointestinal. 